\title{
Depression and suicidality in COPD: understandable reaction or independent disorders?
}

\author{
Ulrich Hegerl and Roland Mergl
}

\section{Affiliations:}

Dept of Psychiatry and Psychotherapy, University of Leipzig, Leipzig, Saxonia, Germany.

\section{Correspondence:}

Ulrich Hegerl, Dept of Psychiatry and Psychotherapy, University of Leipzig, Semmelweisstr. 10, D-04103 Leipzig, Germany.

E-mail: Ulrich.Hegerlamedizin.uni-leipzig.de

ABSTRACT Both depression and chronic obstructive pulmonary disease (COPD) are prevalent, severe and often comorbid disorders. There is a risk of undertreatment for depression in patients with COPD as depressive symptoms, including suicidal tendencies, can erroneously be conceptualised as an understandable reaction to COPD and not as signs of an independent depressive disorder. In this context, the comorbidity rates of COPD and depression, the risk of suicidal behaviour in patients with COPD, and the evidence base for pharmaco- and psychotherapy in these patients are reviewed.

Because symptoms of depression and COPD overlap it remains unclear how far the prevalence of major depression in COPD exceeds that in the general population. The suicide risk appears to be increased in COPD. Methodological studies providing evidence for the antidepressant efficacy of antidepressants or psychotherapy in patients with COPD are lacking. Recommendations for clinicians on how to separate depression from an understandable reaction to COPD are provided.

Given the profound effects of depression on quality of life, life expectancy, COPD prognosis and suicide risk it is important to carefully diagnose and treat depression in patients with COPD according to national guidelines.

@ERSpublications

Comorbid depression has profound effects on COPD prognosis and should not be seen as understandable reaction to COPD http://ow.ly/vNC9G

For editorial comments see page 570 .

Received: Nov 072013 | Accepted after revision: April 102014 | First published online: May 292014

Conflict of interest: Disclosures can be found alongside the online version of this article at erj.ersjournals.com

Copyright @ERS 2014 


\section{Introduction}

Both chronic obstructive pulmonary disease (COPD) and major depressive disorder are prevalent, severe and often comorbid disorders whose outstanding and increasing medical and health policy importance is well documented [1]. The 1-year prevalence of major depressive disorder is $\sim 6.9 \%$ in the general population [2]. Therefore, comorbidity with COPD should be a frequently expected clinical problem [3]. In this case there is the risk of undertreatment for depression because depressive symptoms, including suicidal tendencies, can erroneously be conceptualised as an understandable reaction to COPD and not as signs of an independent depressive disorder (diagnostic criteria are shown in table 1), which has to be treated according to guidelines. However, the suffering associated with major depression as well as the risks, including suicide risk [5], require careful diagnosis because effective treatments are available.

In randomised controlled trials (RCTs) the mean effect sizes of antidepressants in major depression were $\sim 0.30$ for acute treatment and $\sim 0.60$ for relapse prevention, which are comparable to what was found in other areas of medicine [6]. Unless shown otherwise, antidepressant treatments can be expected to be effective in depression with somatic comorbidities. However, evidence for the efficacy of antidepressant treatments would be stronger when specifically shown in patients with comorbid depression and COPD. Therefore, the aims of this review are to: 1) review and critically discuss whether the risk of major depression is increased in patients with COPD; 2) review the risk of suicidal behaviour in patients with COPD; 3 ) give a critical overview of the evidence for efficacy of pharmaco- and psychotherapy in depressed patients with COPD, based on available reviews and more recent studies [7-11]; and 4) provide practical recommendations concerning the diagnosis of and treatment for depression in patients with COPD.

\section{Risk of major depression in patients with COPD}

If COPD is the cause for depression, the comorbidity rates should be higher than what can be expected by chance. However, when interpreting studies on comorbidity rates the methodological problems have to be taken into account. There is a considerable symptom overlap between COPD and major depression, leading to the risk of over-diagnosing depression in epidemiological studies. At the same time, in routine clinical care, the symptom overlap might increase the risk of not recognising a depressive episode in patients with COPD.

\section{TABLE 1 Diagnostic criteria for major depressive disorder ${ }^{\#}$}

\section{Diagnostic Description criteria}

A

Five or more of the symptoms listed below have to be present during the same 14-day period implying a change from previous functioning, at least one of them being either depressed mood or loss of interest or pleasure (Caveat: it is not allowed to include symptoms that can be clearly attributed to other medical conditions):

Depressed mood most of the day and nearly every day

Markedly diminished pleasure or interest in (almost) all activities most of the day and nearly every day

Significant loss of weight (when not dieting) or gain of weight, or decreased or increased appetite nearly every day

In- or hypersomnia nearly every day

Psychomotor retardation or agitation nearly every day

Loss of energy or fatigue nearly every day

Feelings to be worthless or inappropriate or excessive guilt nearly every day

Diminished ability to concentrate or think, or indecisiveness, nearly every day

Recurrent thoughts of death, suicidal ideation without specific plans to commit suicide, or an attempted suicide, or a specific plan for committing suicide

B Symptoms lead to clinically relevant distress or impairment regarding occupational, social, or other important areas of functioning

C The episode cannot be attributed to the physiological effects of a drug or other medical conditions

D

The presence of the major depressive episode cannot be better explained by schizophrenia, schizophreniform disorder, schizoaffective disorder, delusional disorder, or other schizophrenia spectrum and other psychotic disorders

$E$

A manic or hypomanic episode has never been present

\#: Summary of the diagonostic criteria according to the Diagnostic and Statistical Manual of Mental Disorders 5th Edn [4]. 
Major depression and COPD have different key symptoms that are relevant for diagnosis (major depression: depressed mood, loss of interest or pleasure, feelings of excessive guilt and suicidal thoughts [4]; COPD: cough symptoms, sputum production, or dyspnoea indicating airflow limitation [12]). However, both disorders are frequently associated with poor physical activity, withdrawal, anhedonia, fatigue, loss of energy, poor appetite, sleep disturbances and difficulties regarding concentration [13]. The use of standardised clinical interviews for the diagnosis of depressive disorders in patients with COPD count symptoms independent of the overall symptom configuration, thus, leading to high comorbidity rates [14]. Furthermore, direct symptom observations by the clinical assessor, such as psychomotor retardation, are of minor relevance for standardised clinical interviews and cannot be utilised in telephone interviews. In addition, the terminology used in the diagnostic procedure is flawed by mixing up quite different disturbances. "Fatigue" and "lack of energy", which are among the most frequent complaints and symptoms in patients with COPD [15], are too vague to be useful. The term fatigue is used by patients and clinicians for a syndrome associated with increased daytime sleepiness and short sleep onset latencies as found in many nondepressed COPD patients. However, it is also used to describe a syndrome with decreased sleepiness and prolonged sleep onset latencies, as typically found in patients with major depression $[16,17]$.

\section{Prevalence of depression in patients with COPD}

To date, three systematic reviews have focused on whether patients with COPD have an abnormally high prevalence of depression $[3,18,19]$.

In the first review, based on four studies [18], the point prevalence of depression in COPD showed a large range from $7 \%$ to $42 \%$. In two out of the four studies reviewed the point prevalence of depression in COPD patients was significantly higher than that of the controls $[20,21]$. Therefore, the authors could not confirm the hypothesis of an abnormally high risk for depression in COPD patients [18].

Based on more recent findings, a second review [19] ascertained a significantly higher prevalence of depressive symptoms in patients with COPD (24.6\%) than in the controls (11.7\%). Depression was assessed by a variety of methods in each of the studies; five studies used self-report measures and three studies physician-rated measures. Interestingly, the prevalence of depression was not associated with the severity of COPD (i.e. mean forced expiratory volume in $1 \mathrm{~s}$ ).

However, the aforementioned reviews $[18,19]$ did not allow conclusions to be drawn about the prevalence of depressive disorders, because of methodological limitations regarding the assessment of depression. Instead of diagnostic interviews only questionnaires were used. It should be noted that questionnaires are only supportive tools suitable for case-finding and diagnosis of major depression requires a face-to-face interview with the patient.

Similarly, a recent meta-analysis suggested that COPD consistently elevated the risk of depression, with the relative risk being 1.69 [3]. Moreover, the risk of COPD outcomes (COPD exacerbation or incidence of emphysema or chronic bronchitis) was consistently increased by depression (relative risk 1.43) [3].

In addition, 18 more recent studies were identified (table 2). Due to different populations and depression rating scales, there is a wide range in the prevalence of depressive symptoms. In this context it is also of interest to note that the depression risk was not related to the lung function [34] and the objectively measured severity of COPD [19].

Overall, COPD does not seem to be a major cause of depression. The somewhat higher prevalence figures for depression in COPD might be explained to a large degree by the symptom overlap. This interpretation is supported by the fact that in depression COPD is not more prevalent than in the general population $(2.83 \%$ [40] versus $4-10 \%[41])$.

\section{Suicidality in patients with COPD}

The link between COPD and suicidality has been rarely investigated. According to a Swedish national cohort study [42], COPD was significantly and independently associated with an elevated suicide risk. In a recent epidemiological study [43], the link between COPD and suicidal ideation and suicide attempts was analysed. Whereas $27.2 \%$ of the COPD patients stated that they had seriously thought about committing suicide this was the case in only $19.6 \%$ of subjects without COPD. The corresponding odds ratio (1.74) was significant. The difference between these two groups regarding a self-reported lifetime history of suicide attempts was even more pronounced and significant (15.0\% for COPD patients, $6.6 \%$ for subjects without $\mathrm{COPD} ; \mathrm{OR}=2.29$ ). According to a large case-control study [44] the relative risk of suicide was significantly elevated among patients with COPD compared with patients without major chronic illnesses $(3.1 \%$ versus $1.9 \%$, respectively; $\mathrm{OR}=1.80)$. 
TABLE 2 Prevalence of depressive symptoms/disorders in chronic obstructive pulmonary disease (COPD) patients reported in studies published from 2011 to 2013

First author [ref.]
Assessment tools

PHQ-9

DE [22]

HAYASHI [23]

HADS-D

GoodWIN [24]

Joo [25]

LOERBROKS [26]

Lou [27]

MARINHo [28]

OBRadoVIC [29]

SCHNeLL [30]

ARIMURA [31]

HORITA [32]

IGUCHI [33]

LeE [34]

Papaloannou [35]

\section{QIAN [36]}

SHARMA [37]

WARMENHOVEN [38]

ZHANG [39]
CIDI diagnosis of major depression Standardised questionnaires on comorbidities associated with COPD GDS- 15 sum score $\geqslant 4$ points

HADS-D $\geqslant 8$ points

GDS-15

HDRS

Physicians' lifetime diagnosis of depression

CES-D score $\geqslant 10$ points

$$
\text { SF-GDS } \geqslant 6 \text { points }
$$

Japanese version of the CES-D sum score $\geqslant 16$ points PHQ-9 $\geqslant 10$ points BDI-I sum score $\geqslant 19$ points

Clinical ICD-9-CM diagnoses of depressive disorders

Global Mental Health Assessment Tool - Primary Care and General Health version

General practitioners' lifetime diagnosis of depressive disorders

Face-to-face questionnaire

Patients

Prevalence of depression \%

100 consecutively recruited Indian patients with stable COPD

80 outpatients and 51 inpatients suffering from stable COPD in Japan

147 COPD patients (self report) in the USA

354 COPD patients (subsample of 9744 subjects from the Korean population)

7995 COPD patients from a large population sample from southern China

1100 outpatients with COPD from China and 1100 healthy controls

40 elderly COPD patients from Brazil 40 COPD patients from Serbia

995 COPD patients (aged $\geqslant 45$ years) from the USA

52 consecutively recruited and clinically stable COPD patients in the pulmonary departments of five hospitals in Japan

84 consecutive, stable COPD outpatients in a Japanese community hospital

74 COPD patients from long-term Japanese inpatient rehabilitation facilities 803 COPD inpatients from Korea

230 consecutive COPD inpatients in departments of respiratory medicine in two tertiary hospitals in Greece

75699 US beneficiaries ${ }^{\#}$ (minimum age 65 years) with a diagnosis of COPD

52 consecutive patients with stable COPD attending a respiratory disease clinic in Northern India

982 Dutch patients with COPD, cardiovascular disease and cancer in the last phase of their lives 7597 COPD patients from China
72

40.5

24.8

COPD: 18.7; non-COPD: 17.4

22.9

COPD: 35.7 ; controls: 7.2

22.5

20.0

20.6

29

23.8

39.6

21.6

COPD: 19.2; controls: 3.4

PHQ-9: patient health questionnaire-9; HADS-D: hospital anxiety and depression scale depression subscale; CIDI: composite international diagnostic interview; GDS-15: geriatric depression scale 15-item version; HDRS: Hamilton depression rating scale; CES-D: Center for Epidemiologic Studies depression scale; SF-GDS: short-form geriatric depression scale; BDI-I: Beck's depression inventory I; ICD-9-CM: international classification of diseases, 9th revision, clinical modification. ${ }^{\#}$ : persons enrolled in Medicare parts A, B and D in the USA.

\section{Therapeutic strategies for depression in patients with COPD}

For four reasons the treatment of depression is important in patients with COPD. 1) Depression in patients with COPD goes along with a markedly reduced quality of life [45, 46], increased healthcare use [47], and an elevated risk of exacerbations and hospitalisations [48]. 2) Effective treatments for depression (antidepressants and psychotherapy) are available [49]. 3) Depression has negative effects on outcomes of pulmonary rehabilitation (especially dyspnoea) in patients with COPD [50]. 4) There is a significant association between depression and lower adherence to treatment in patients with COPD [51].

\section{Effects of antidepressants}

Effects of tricyclic antidepressants

Only three double-blind clinical trials were found involving the tricyclic antidepressants (TCAs) doxepin, imipramine (combined with diazepam) and nortriptyline (table 3) [52-54].

One study [54] reported a large effect size for nortriptyline (Cohen's d -1.07) compared with placebo [10]; however, as only 30 patients completed the study it was strongly underpowered. Due to even more serious methodological limitations of the remaining studies no firm conclusions can be drawn concerning TCAs in patients with comorbid depression and COPD. In addition, the acceptability of TCAs in this patient group 
TABLE 3 Antidepressant drugs in patients with chronic obstructive pulmonary disease (COPD) and depressive disorders: blinded treatment trials with tricyclic antidepressants

Characteristics of the study

Study design

Participants

Interventions

Outcomes

Main results

\section{Randomisation procedure}

Support by manufacturers

Verified clinical COPD diagnosis

Assessment of depressive

episodes in the past/family

history of affective disorders/

core symptoms of depression

Assessment of compliance
Doxepin [52]

Imipramine [53]

Nortriptyline [54]

$$
\begin{gathered}
\text { Randomised double-blind, } \\
\text { placebo-controlled crossover } \\
\text { clinical trial } \\
12 \text { outpatients with stage III of } \\
\text { COPD and severe depression } \\
\text { (9 completed) } \\
\text { 6-week treatment with either } \\
\text { doxepin hydrochloride } \\
\text { (flexible doses, maximally } \\
25 \text { mg.day }{ }^{-1} \text { ) or placebo } \\
\text { BDI (sum score) } \\
\text { No significant decrease of } \\
\text { depression scores (doxepin: } \\
\text { Cohen's d 0.37 }{ }^{\#} \text {; placebo: } \\
\text { Cohen's d } 0.46^{\#} \text {; comparable } \\
\text { antidepressive effects } \\
\text { (low-middle) for doxepin } \\
\text { and placebo } \\
\text { No information available }
\end{gathered}
$$

No information available Yes

No

Yes, by drug monitoring (pill count)
Double-blind clinical trial with

recruitment of patients on alternate basis; no placebo control

54 consecutively recruited patients with all stages of COPD and "depressive neurosis"

Imipramine combined with a

benzodiazepine (diazepam) plus bronchodilators versus bronchodilators alone BDI (sum score)

Imipramine-diazepam combination was associated with faster recovery in depressed patients with COPD

Diazepam-induced respiratory

failure is a serious side-effect

According to a subclassification of patients on alternate basis No information available Yes

No

No
Randomised double-blind, placebo-controlled clinical trial

36 inpatients with COPD (stages II-III) and depression according to DSM-III (30 completed)

12-week treatment with either nortriptyline or placebo lweekly increase of $0.25 \mathrm{mg} \cdot \mathrm{kg}^{-1}$ up to

$1 \mathrm{mg} \cdot \mathrm{kg}^{-1}$ of body weight)

CGI score, HDRS (sum score)

Nortriptyline was significantly

superior to placebo (Cohen's d

$-1.07^{\#}$ for the difference in reduction of HDRS total scores between nortriptyline and placebol

By a table of random numbers

$$
\begin{gathered}
\text { Yes (partly) } \\
\text { Yes } \\
\text { No }
\end{gathered}
$$

DSM-III: Diagnostic and Statistical Manual of Mental Disorders, 3rd revision; BDI: Beck's depression inventory; CGI: clinical global improvement scale; HDRS: Hamilton depression rating scale. ${ }^{\#}$ : effect size as computed for a review [10] on effects of antidepressants and psychotherapy on depression in COPD patients.

is clearly limited by their side-effects (especially anticholinergic and antihistaminergic side-effects such as sedation) [10].

Regarding effects of TCAs on lung function in patients with COPD, neither effects on spirometry [52-54] or on peak expiratory flow rates [53] and respiratory function measured by arterial blood gases [54] have been found.

\section{Effects of selective serotonin reuptake inhibitors}

Four selective serotonin reuptake inhibitor (SSRI) trials with sample sizes $>10$ were detected, examining citalopram, fluoxetine and paroxetine (table 4).

Overall, the available studies did not have the statistical power to detect superiority of SSRI over placebo [55-58]. In addition, the drop-out rates in these trials were high (21-50\%), and a variety of depression rating scales was used (table 4) [10], Frustration with multiple medications and the fear of side-effects have been discussed as the reasons for high dropout rates for depressed COPD patients reported in these antidepressant trials [10]. Negative effects of SSRIs on lung function in depressed patients with COPD do not appear to be a major problem. In the case of paroxetine, no significant changes in lung function were found [58]; respiratory symptoms did not worsen and dyspnoea slightly improved [57].

\section{Possible adverse effects of antidepressants on lung function}

There are some caveats regarding the interaction between antidepressant drugs and drugs commonly used in COPD (table 5). Whereas there are no principal contraindications of antidepressants in COPD patients, combination of fluvoxamine and St. John's wort with theophylline is contraindicated [61]. Concerning bupropion there is the risk of involuntary overdose, because this substance is also prescribed under a different brand name for the indication of smoking cessation [59]. 
TABLE 4 Antidepressant drugs in patients with chronic obstructive pulmonary disease (COPD) and depressive disorders: blinded treatment trials with selective serotonin reuptake inhibitors

$\begin{array}{llll}\begin{array}{l}\text { Study } \\ \text { characteristics }\end{array} & \text { Citalopram [55] } & \text { Fluoxetine [56] } & \text { Paroxetine [57] }\end{array}$

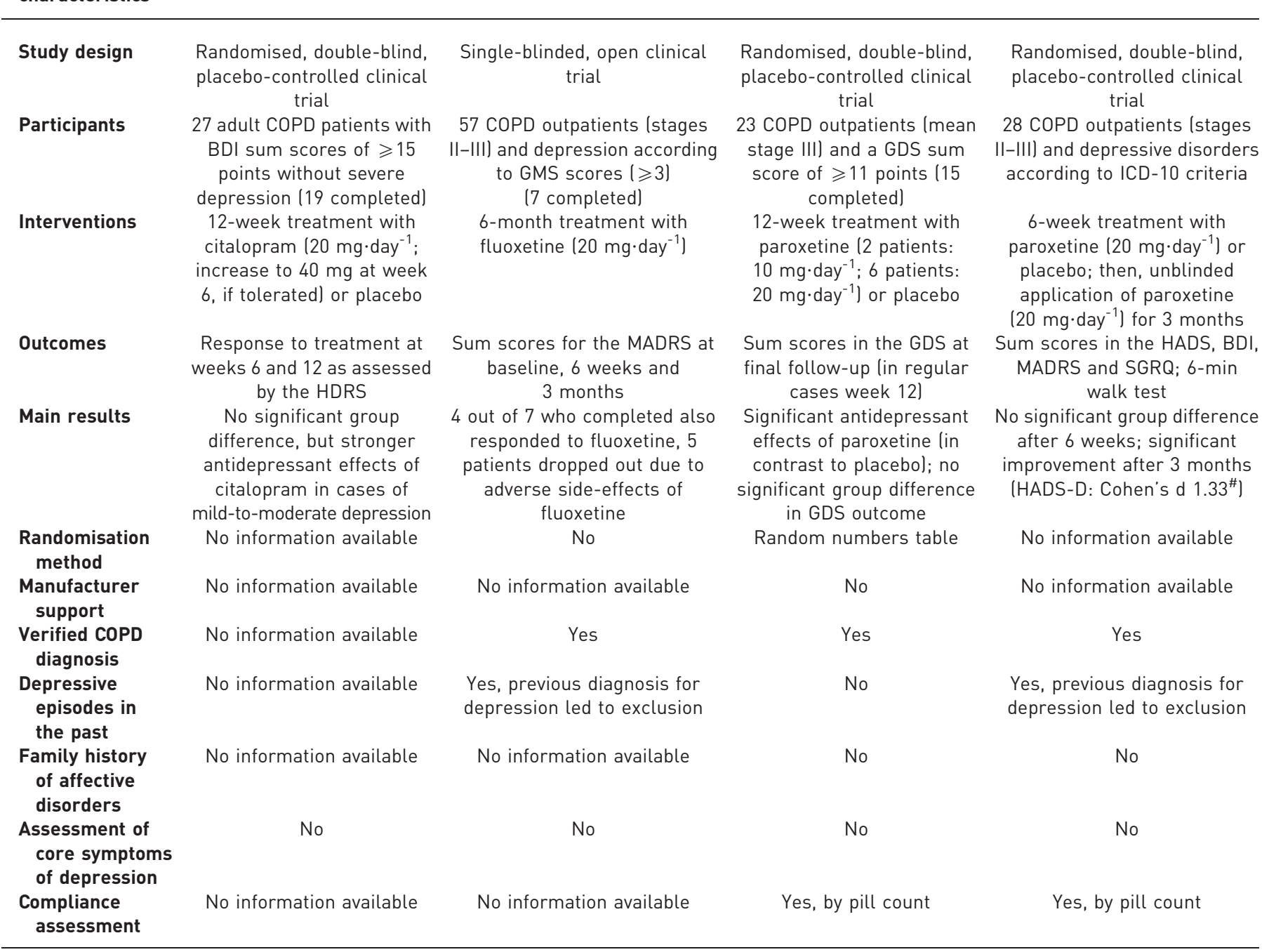

BDI: Beck's depression inventory; GDS: geriatric depression screening scale; GMS: geriatric mental state schedule; ICD-10: international classification of diseases, 10th revision; HDRS: Hamilton depression rating scale; MADRS: Montgomery-Asberg depression rating scale; HADS: hospital anxiety and depression scale; SGRQ: St George's Respiratory Questionnaire; HADS-D: HADS depression subscale. \#: effect sizes as computed for a review by FRITZSCHE et al. [10] on effects of antidepressants and psychotherapy on depression in COPD patients.

Treatment for suicidal or psychotic major depression in COPD patients can require the use of antipsychotics. Typical and atypical antipsychotics are often combined with antidepressants in the treatment of patients with psychotic major depression. Some atypical antipsychotics have an antidepressant effect on their own and are used without additional antidepressants in the treatment of major depression. So far, adverse effects of typical and atypical antipsychotics in COPD patients have not been reported.

\section{Effects of psychotherapy}

The efficacy of cognitive and behavioural interventions for depression in patients with COPD (especially cognitive behavioural therapy $(\mathrm{CBT})$ ) was well summarised in a recent review [10]. Six RCTs were available.

CBT was associated with a significant reduction of depressive symptoms in patients with COPD in the majority of studies. However, no strong conclusions can be drawn because a publication bias is probable. Moreover, depressive symptoms also strongly decrease in the placebo arms of the RCTs. Whether these improvements are larger than those in the control condition is important. To date, only one study found 
TABLE 5 Adverse interactions between antidepressants and drugs commonly used in patients with chronic obstructive pulmonary disease (COPD)

\section{Drugs containing bupropion (typically administered for smoking cessation in patients with COPD)} Inhaled bronchodilators (e.g. ipratropium, salbutamol) Theophylline

Corticosteroids (e.g. beclomethasone, prednisolone) Leukotriene antagonists (e.g. montelukast)
Bupropion

No antidepressant drug is specifically contraindicated

Fluvoxamine (due to inhibition of theophylline metabolism)

St. John's wort (due to increased theophylline metabolism)

No antidepressant drug is specifically contraindicated

No antidepressant drug is specifically contraindicated
Any other antidepressant drugs

(e.g. other SSRIs)

Any

Any other antidepressant drugs (e.g. other SSRIs)

Any

Any

SSRI: selective serotonin reuptake inhibitor. Further details can be found in $[59,60]$.

CBT to have stronger antidepressant effects in COPD patients than standard care [62]. Other studies including one with a waiting list as the control group failed to find significant effects. In line with these findings, a recent meta-analysis revealed only small, nonsignificant effects of CBT on self-reported symptoms of depression in COPD patients [63]. In comparison to COPD education, CBT has been shown to have a comparable antidepressant effect [64].

\section{Practical consequences}

Keeping in mind the symptom overlap for depression and COPD, it is likely that COPD-related symptoms add to the number of symptoms required to formally diagnose a depressive disorder, thereby leading to an overestimation of the prevalence of depression in COPD patients. This bias could explain the increased prevalence of depression in patients with COPD reported in some of the epidemiological studies. Possibly, without this bias, the depression prevalence in COPD patients would not be much higher than that expected by chance. This would argue against COPD being a strong causal factor in the pathogenesis of depression. This view is supported by the findings that depression prevalence is not related to the severity of COPD [19] and that in patients with major depression the prevalence of COPD is even lower than in the general population [40].

The independence of depression from COPD is further supported by the fact that $23 \%$ of these patients had already experienced depressive episodes before the onset of COPD [65]. This reasoning underlines that caution is required when interpreting depression mainly as an understandable reaction to COPD, even when the patients themselves name COPD as the reason for their despair. This raises the question of how clinicians can separate a normal psychological reaction to severe COPD from a major depression. The following criteria and depression-specific symptoms are helpful in everyday practice in identifying the presence of a major depression: feelings of guilt ("I am a burden for my family"); profound anhedonia ("even when my grandchild visits me, I cannot enjoy it"); emotional numbness ("I can feel no feelings at all, not even grief, as if I am dead"); high inner tension (“...as if I am always on edge"); difficulties in relaxing and falling asleep (exhausted, but not sleepy); earlier depressive episodes; positive family history of affective disorders; suicidal tendencies; and delusional depression (typically delusions of guilt or wrong doing, delusion of poverty or hypochondriacal delusion).

Care has to be taken not to oversee an acute risk of suicide. An active exploration is necessary in every patient with a relevant depressive syndrome.

Concerning pharmacotherapy for depression it has to be concluded that there is sufficient evidence neither for the efficacy of antidepressants in depressed patients with COPD nor for the lack of efficacy. Therefore, until shown to the contrary, it has to be assumed that antidepressants are effective in this subgroup of patients as they are in patients without COPD. Because of the less problematic side-effect profile and the safety in overdose SSRIs should be preferred to TCAs. According to most guidelines antidepressants should be offered, especially in patients with moderate-to-severe depression. In this context, it has to be emphasised that antidepressants have to be prescribed when a depressive disorder is fully diagnosed in order to avoid their overprescription. According to the diagnostic criteria for major depression (table 1) symptoms which 
might be sufficiently explained by COPD (e.g. sleep problems) in a patient should not be used additionally as a symptom for diagnosing comorbid major depression.

In view of the fact that $>50 \%$ of patients with COPD and an even higher percentage of patients with major depression suffer from sleep problems [66], hypnotics such as benzodiazepines might be considered as a treatment option. Indeed, benzodiazepines were effective in ameliorating quality of sleep in this patient group [67]. However, the well-known risk of drug dependence forbids the long-term use of these drugs. In addition, several case reports and case series have reported adverse pulmonary events associated with benzodiazepines in COPD patients [68], although this is not confirmed by all studies [69].

Concerning the efficacy of psychotherapy of depression in COPD no convincing evidence has been provided to date. However, since there are no reasons to assume a lack of efficacy for psychotherapy in these patients, treatment according to guidelines has to be provided. CBT is the psychotherapy with the best evidence for efficacy in patients with major depression [70]. In line with this, the recently published COPD-specific UK National Institute for Health and Care Excellence guidelines recommend "identifying and managing anxiety and depression" [60].

\section{Acknowledgements}

We are very grateful to Michael Hellwig, Mona Khalid and Peter Kreil (Takeda Pharmaceuticals, Zurich, Switzerland) who improved the manuscript to a considerable extent with their helpful comments. Moreover, we thank Matthias Binek and Lou Mini (Takeda Pharmaceuticals, Zurich, Switzerland) for their participation in the internal Takeda review of this manuscript.

\section{References}

1 Lopez AD, Mathers CD. Measuring the global burden of disease and epidemiological transitions: 2002-2030. Ann Trop Med Parasitol 2006; 100: 481-499.

2 Wittchen HU, Jacobi F, Rehm J, et al. The size and burden of mental disorders and other disorders of the brain in Europe 2010. Eur Neuropsychopharmacol 2011; 21: 655-679.

3 Atlantis E, Fahey P, Cochrane B, et al. Bidirectional associations between clinically relevant depression or anxiety and chronic obstructive pulmonary disease (COPD): a systematic review and meta-analysis. Chest 2013; 144: 766-777.

4 American Psychiatric Association. Diagnostic and Statistical Manual of Mental Disorders. 5th Edn. Arlington, American Psychiatric Association, 2013.

5 Cavanagh JT, Carson AJ, Sharpe M, et al. Psychological autopsy studies of suicide: a systematic review. Psychol Med 2003; 33: 395-405.

6 Leucht S, Hierl S, Kissling W, et al. Putting the efficacy of psychiatric and general medicine medication into perspective: review of meta-analyses. Br J Psychiatry 2012; 200: 97-106.

7 Baraniak A, Sheffield D. The efficacy of psychologically based interventions to improve anxiety, depression and quality of life in COPD: a systematic review and meta-analysis. Patient Educ Couns 2011; 83: 29-36.

8 Cafarella PA, Effing TW, Usmani ZA, et al. Treatments for anxiety and depression in patients with chronic obstructive pulmonary disease: a literature review. Respirology 2012; 17: 627-638.

9 Coventry PA, Gellatly JL. Improving outcomes for COPD patients with mild-to-moderate anxiety and depression: a systematic review of cognitive behavioural therapy. Br J Health Psychol 2008; 13: 381-400.

10 Fritzsche A, Clamor A, von Leupoldt A. Effects of medical and psychological treatment of depression in patients with COPD - a review. Respir Med 2011; 105: 1422-1433.

11 Putman-Casdorph H, McCrone S. Chronic obstructive pulmonary disease, anxiety, and depression: state of the science. Heart Lung 2009; 38: 34-47.

12 Celli BR, MacNee W. Standards for the diagnosis and treatment of patients with COPD: a summary of the ATS/ERS position paper. Eur Respir J 2004; 23: 932-946.

13 Yohannes AM, Willgoss TG, Baldwin RC, et al. Depression and anxiety in chronic heart failure and chronic obstructive pulmonary disease: prevalence, relevance, clinical implications and management principles. Int J Geriatr Psychiatry 2010; 25: 1209-1221.

14 Linden M, Muschalla B. Standardized diagnostic interviews, criteria, and algorithms for mental disorders: garbage in, garbage out. Eur Arch Psychiatry Clin Neurosci 2012; 262: 535-544.

15 Joshi M, Joshi A, Bartter T. Symptom burden in chronic obstructive pulmonary disease and cancer. Curr Opin Pulm Med 2012; 18: 97-103.

16 Hegerl U, Lam RW, Malhi GS, et al. Conceptualising the neurobiology of fatigue. Aust N Z J Psychiatry 2013; 47: 312-316.

17 Hegerl U, Wilk K, Olbrich S, et al. Hyperstable regulation of vigilance in patients with major depressive disorder. World J Biol Psychiatry 2012; 13: 436-446.

18 van Ede L, Yzermans CJ, Brouwer HJ. Prevalence of depression in patients with chronic obstructive pulmonary disease: a systematic review. Thorax 1999; 54: 688-692.

19 Zhang MW, Ho RC, Cheung MW, et al. Prevalence of depressive symptoms in patients with chronic obstructive pulmonary disease: a systematic review, meta-analysis and meta-regression. Gen Hosp Psychiatry 2011; 33: 217-223.

20 McSweeny AJ, Grant I, Heaton RK, et al. Life quality of patients with chronic obstructive pulmonary disease. Arch Intern Med 1982; 142: 473-478.

21 Prigatano GP, Wright EC, Levin D. Quality of life and its predictors in patients with mild hypoxemia and chronic obstructive pulmonary disease. Arch Intern Med 1984; 144: 1613-1619.

22 De S. Prevalence of depression in stable chronic obstructive pulmonary disease. Indian J Chest Dis Allied Sci 2011; 53: 35-39. 
Hayashi Y, Senjyu H, Iguchi A, et al. Prevalence of depressive symptoms in Japanese male patients with chronic obstructive pulmonary disease. Psychiatry Clin Neurosci 2011; 65: 82-88.

24 Goodwin RD, Lavoie KL, Lemeshow AR, et al. Depression, anxiety, and COPD: the unexamined role of nicotine dependence. Nicotine Tob Res 2012; 14: 176-183.

25 Joo H, Park J, Lee SD, et al. Comorbidities of chronic obstructive pulmonary disease in Koreans: a populationbased study. J Korean Med Sci 2012; 27: 901-906.

26 Loerbroks A, Jiang CQ, Thomas GN, et al. COPD and depressive symptoms: findings from the Guangzhou Biobank Cohort Study. Ann Behav Med 2012; 44: 408-415.

27 Lou P, Zhu Y, Chen P, et al. Prevalence and correlations with depression, anxiety, and other features in outpatients with chronic obstructive pulmonary disease in China: a cross-sectional case control study. BMC Pulm Med 2012; 12: 53.

28 Marinho PE, Castro CM, Raposo MC, et al. Depressive symptoms, inflammatory markers and body composition in elderly with and without chronic obstructive pulmonary disease (COPD). Arch Gerontol Geriatr 2012; 54: 453-458.

29 Obradovic LM, Pesut DP, Maric D, et al. Symptoms of anxiety and depression in patients with chronic obstructive pulmonary disease. Pneumologia 2012; 61: 92-96.

30 Schnell K, Weiss CO, Lee T, et al. The prevalence of clinically-relevant comorbid conditions in patients with physician-diagnosed COPD: a cross-sectional study using data from NHANES 1999-2008. BMC Pulm Med 2012; 12: 26.

31 Arimura Y, Yamazaki S, Yanagi S, et al. Clinical usefulness of the two-question assessment tool for depressive symptoms in Japanese patients with chronic obstructive pulmonary disease. Lung 2013; 191: 101-107.

32 Horita N, Kaneko T, Shinkai M, et al. Depression in Japanese patients with chronic obstructive pulmonary disease: a cross-sectional study. Respir Care 2013; 58: 1196-1203.

33 Iguchi A, Senjyu H, Hayashi Y, et al. Relationship between depression in patients with COPD and the percent of predicted FEV1, BODE index, and health-related quality of life. Respir Care 2013; 58: 334-339.

34 Lee YS, Park S, Oh YM, et al. Chronic obstructive pulmonary disease assessment test can predict depression: a prospective multi-center study. J Korean Med Sci 2013; 28: 1048-1054.

35 Papaioannou AI, Bartziokas K, Tsikrika S, et al. The impact of depressive symptoms on recovery and outcome of hospitalised COPD exacerbations. Eur Respir J 2013; 41: 815-823.

36 Qian J, Simoni-Wastila L, Langenberg P, et al. Effects of depression diagnosis and antidepressant treatment on mortality in Medicare beneficiaries with chronic obstructive pulmonary disease. J Am Geriatr Soc 2013; 61: 754-761.

37 Sharma BB, Singh S, Sharma VK, et al. Psychiatric morbidity in chronic respiratory disorders in an Indian service using GMHAT/PC. Gen Hosp Psychiatry 2013; 35: 39-44.

38 Warmenhoven F, Bor H, Lucassen $\mathrm{P}$, et al. Depressive disorder in the last phase of life in patients with cardiovascular disease, cancer, and COPD: data from a 20-year follow-up period in general practice. Br J Gen Pract 2013; 63: e303-e308.

39 Zhang L, Lou P, Zhu Y, et al. Impact of risk factors, activities and psychological disorders on the health of patients with chronic obstructive pulmonary disease in China: a cross-sectional study. BMC Public Health 2013 ; 13 : 627.

40 Gabilondo A, Vilagut G, Pinto-Meza A, et al. Comorbidity of major depressive episode and chronic physical conditions in Spain, a country with low prevalence of depression. Gen Hosp Psychiatry 2012; 34: $510-517$.

41 Halbert RJ, Isonaka S, George D, et al. Interpreting COPD prevalence estimates: what is the true burden of disease? Chest 2003; 123: 1684-1692.

42 Crump C, Sundquist K, Sundquist J, et al. Sociodemographic, psychiatric and somatic risk factors for suicide: a Swedish national cohort study. Psychol Med 2014; 44: 279-289.

3 Goodwin RD. Is COPD associated with suicide behavior? J Psychiatr Res 2011; 45: 1269-1271.

44 Webb RT, Kontopantelis E, Doran T, et al. Suicide risk in primary care patients with major physical diseases: a casecontrol study. Arch Gen Psychiatry 2012; 69: 256-264.

45 Yildirim A, Așilar RH, Bakar N, et al. Effect of anxiety and depression on self-care agency and quality of life in hospitalized patients with chronic obstructive pulmonary disease: a questionnaire survey. Int J Nurs Pract 2013; 19: $14-22$.

46 Hanania NA, Müllerova H, Locantore NW, et al. Determinants of depression in the ECLIPSE chronic obstructive pulmonary disease cohort. Am J Respir Crit Care Med 2011; 183: 604-611.

47 García-Polo C, Alcázar-Navarrete B, Ruiz-Iturriaga LA, et al. Factors associated with high healthcare resource utilisation among COPD patients. Respir Med 2012; 106: 1734-1742.

48 Ito K, Kawayama T, Shoji Y, et al. Depression, but not sleep disorder, is an independent factor affecting exacerbations and hospitalization in patients with chronic obstructive pulmonary disease. Respirology 2012; 17: 940-949.

49 Cuijpers P, van Straten A, van Oppen P, et al. Are psychological and pharmacologic interventions equally effective in the treatment of adult depressive disorders? A meta-analysis of comparative studies. J Clin Psychiatry 2008; 69: 1675-1685.

50 Carreiro A, Santos J, Rodrigues F. Impact of comorbidities in pulmonary rehabilitation outcomes in patients with chronic obstructive pulmonary disease. Rev Port Pneumol 2013; 19: 106-113.

51 Turan $\mathrm{O}$, Yemez B, Itil O. The effects of anxiety and depression symptoms on treatment adherence in COPD patients. Prim Health Care Res Dev 2014; 15: 244-251.

52 Light RW, Merrill EJ, Despars J, et al. Doxepin treatment of depressed patients with chronic obstructive pulmonary disease. Arch Intern Med 1986; 146: 1377-1380.

53 Sharma TN, Goyal RL, Gupta PR, et al. Psychiatric disorders in COPD with special reference to the usefulness of imipramine-diazepam combination. Indian J Chest Dis Allied Sci 1988; 30: 263-268.

54 Borson S, McDonald GJ, Gayle T, et al. Improvement in mood, physical symptoms, and function with nortriptyline for depression in patients with chronic obstructive pulmonary disease. Psychosomatics 1992; 33: 190-201.

55 Silvertooth EJ, Doraiswamy PM, Clary GL, et al. Citalopram and quality of life in lung transplant recipients. Psychosomatics 2004; 45: 271-272.

56 Yohannes AM, Connolly MJ, Baldwin RC. A feasibility study of antidepressant drug therapy in depressed elderly patients with chronic obstructive pulmonary disease. Int J Geriatr Psychiatry 2001; 16: 451-454. 
57 Lacasse Y, Beaudoin L, Rousseau L, et al. Randomized trial of paroxetine in end-stage COPD. Monaldi Arch Chest Dis 2004; 61: 140-147.

58 Eiser N, Harte R, Spiros K, et al. Effect of treating depression on quality-of-life and exercise tolerance in severe COPD. COPD 2005; 2: 233-241.

59 DGPPN. S3 Guideline/National Guideline for Care of Unipolar Depression: Long version. [S3-Leitlinie/Nationale VersorgungsLeitlinie Unipolare Depression: Langfassung]. Version 1.3. Berlin, Düsseldorf, DGPPN, ÄZQ, AWMF, 2012.

60 National Institute for Health and Clinical Excellence. Chronic Obstructive Pulmonary Disease: Management of Chronic Obstructive Pulmonary Disease in Adults in Primary and Secondary Care (Partial Update). NICE Clinical Guideline 101. London, NICE, 2010.

61 National Institute for Health and Care Excellence. Depression in Adults with a Chronic Physical Health Problem: Treatment and Management. NICE Clinical Guideline 91. London, NICE, 2009.

62 Hynninen MJ, Bjerke N, Pallesen S, et al. A randomized controlled trial of cognitive behavioral therapy for anxiety and depression in COPD. Respir Med 2010; 104: 986-994.

63 Coventry PA, Bower P, Keyworth C, et al. The effect of complex interventions on depression and anxiety in chronic obstructive pulmonary disease: systematic review and meta-analysis. PLoS One 2013; 8: e60532.

64 Kunik ME, Veazey C, Cully JA, et al. COPD education and cognitive behavioral therapy group treatment for clinically significant symptoms of depression and anxiety in COPD patients: a randomized controlled trial. Psychol Med 2008; 38: 385-396.

65 Schneider C, Jick SS, Bothner U, et al. COPD and the risk of depression. Chest 2010; 137: 341-347.

66 Roth T. Hypnotic use for insomnia management in chronic obstructive pulmonary disease. Sleep Med 2009; 10: $19-25$.

67 Stege G, Vos PJ, van den Elshout FJ, et al. Sleep, hypnotics and chronic obstructive pulmonary disease. Respir Med 2008; 102: 801-814.

68 George CF, Bayliff CD. Management of insomnia in patients with chronic obstructive pulmonary disease. Drugs 2003; 63: 379-387.

69 Larsen J, Arnberg A, Brøsen K. Tramadol og oxazepam. Effekt pa lungefunktionen hos aeldre patienter med kronisk obstruktiv lungesygdom [Tramadol and oxazepam. Effect on pulmonary function in elderly patients with chronic obstructive lung disease]. Ugeskr Laeger 2001; 163: 458-460.

70 Tolin DF. Is cognitive-behavioral therapy more effective than other therapies? A meta-analytic review. Clin Psychol Rev 2010; 30: 710-720. 